\title{
PROMISING SITES FOR OIL AND GAS NADYM DEPRESSIONS
}

-

R. I. Safin

юменский индустри льный университет, г.юмень

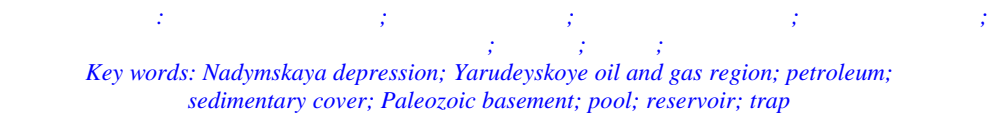

дымск я вп дин - крупн я тектоническ я единиц I порядк дым- зовской синеклизы, з ним ющ я обширную территорию от южных берегов бской губы до ибирских в лов и включ ющ я п дно- рудейскую и нловскую вп дины, р зделенные рудейским мег в лом. схеме нефтег зогеологического р йониров ния

дымск я вп дин соответствует рудейскому нефтег зоносному р йону роловской нефтег зоносной обл сти п дно- ибирской провинции.

урение н поисковых площ дях велось к к н крупных положительных структуp x ( рудейский мег в л, ерхнен дымск я моноклин ль), т к и н отриц тельных, что в результ те позволило открыть месторождения и т м, и т м. ричем н юге территории месторождения многопл стовые, в отличие от северных земель.

скрытый и изученный р зрез ост ется кр йне нер вномерным. олностью или ч стично юрские отложения были вскрыты в основном н бортовых уч стк х. ких скв жин 73 из 142 пробуренных. ще шесть скв жин вскрыли п леозойский фунд мент, предст вленный вулк нит ми и мет морфизов нными сл нц ми. ст льные 63 ост новлены в пород х нижнего мел .

сновные перспективы нефтег зоносности, н чин я с первых поисковых скв жин угинск я 82, 83 (1963-1964 гг.), дымск я 1 (1967 г.) и других, связыв лись в первую очередь с пл ст ми группы ( н лог ми продуктивных пл стов ском своде), д лее - с менее изученными чимовскими линзовидными песч ными тел ми и со сл бопрониц емыми песч ник ми и левролит ми тюменской свиты. учную б зу поисково-р зведочных р бот вели ученые п иб совместно с производственными сил ми гл вк . итоге прогнозы . . умов , . . нищук и других исследов телей опр вд лись н ндибинской, ензитской и других площ дях. озднее геологи иб обоснов ли открытие высокодебитного рудейского и угинского месторождений.

о состоянию н 01.01.2016г. н территории рудейского открыто 11 месторождений , выявленных в ди п зоне от средней юры до верхнего мел включительно: ндибинское - 1 нефтян яз лежь в пл сте 6 ; ензитское -1 нефтян я з лежь в пл сте 2-5; рудейское - 3 з лежи в пл ст х $\quad 2(\quad), \quad 2-4(\quad)$ и ${ }_{12}(\quad)$; п дно- едвежье - 1 з лежь нефти в пл сте ${ }_{2}^{1}$; дымское -2 лежи в пл ст х ${ }_{7}$ и ${ }_{12} ;$ уцеяхское -1 з лежь нефти в пл сте $\mathrm{ч}_{3}{ }_{3}$; реднен дымское 13 лежь нефти в пл сте 2 ; ерхнех рловское - 5 з лежей в пл ст х $ч_{2}\left(\right.$ ), ч $_{3}$ 
( ),$\quad \Psi_{4}\left(\right.$ ), $\quad 2\left(\right.$ ), $\quad 2$ ( ); льниковское -5 з лежей в пл ст х $\quad 7\left(\right.$ ), $\quad 8^{2-1}($ ),

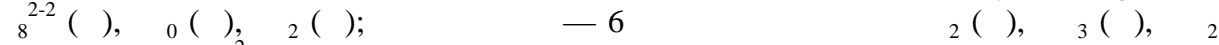


ст 2 .

сего выявлено 27 з лежей , из них 20 нефтяных, 6 г зоконденс тных и 1 г зоконденс тно-нефтян я, то есть нефтян я з лежь с г зоконденс тной ш пкой.

ерспективы нефтег зоносности. ефтег зопроявления - в жный критерий оценки перспектив нефтег зоносности новых и сл боизученных территорий. силу регион льного процесс нефтег зообр зов ния по с мой его природе лок льные н ходки нефтепроявлений в одном из пунктов вп дины д ют пр во р сценив ть их к к пок 3 тель нефтеносности территории в целом и к к свидетельство н личия н логичных призн ков в других ч стях, н структур х, не з тронутых глубоким бурением. к, в 38 скв жин х $з$ предел ми контуров месторождений уст новлены нефтепроявления, выр ж ющиеся в выпот х нефти, з п хе бензин , н личии пленок нефти и сл бых (непромышленных) притоков , продуктивном х р ктере н сыщения по и г зовому к рот жу.

леозойский фунд мент к к перспективный объект изучен всего шестью скв жин ми. реднен дымской 71 получен пленк нефти с водой из коры выветрив ния мет морфизов нной песч но-глинистой толщи. ост льных скв жин х приток не получено, либо получен вод . к, н пример, в скв. 6 ндибинской при з бое 3697 м н ч лись интенсивные г зо- и водопроявления. кв жин перелив л пл стовой водой дебитом $60 \mathrm{~m}^{3} /$ сут н 8 мм в штуцере. скв. 7 дымской при испыт нии двух объектов п леозоя в первом объекте приток не получено, во втором отмечен пл стов я вод дебитом $0,35 \mathrm{~m}^{3} /$ сут. скв. 2 рудейской при испыт нии п леозоя и низов юры в интерв ле 3 182-3 196 м был получен приток пл стовой воды дебитом $9 \mathrm{~m}^{3} /$ сут. то свидетельствует о н личии коллекторов в доюрском основ нии н д нной территории.

кже рудейский межгорный прогиб перспективен н нефтег зоносность по н логии с йс нским, где з лежи нефти открыты в пермских отложениях [1]. ерспективен и верхнеп леозойский ос дочный чехол, перекрыв ющий дымский срединный м ссив.

мпейск я серия. н стоящий момент единственные призн ки нефтег зоносности получены именно в рудейском • п р метрической скв жине рудейской 38 поднят нефтен сыщенный керн в виде выпотов и выс чив ния из м ссивных и трещинов тых левролитов и глинистых песч ников. ри испыт нии скв жины получен пленк нефти из двух интерв лов. ерспективным д нный объект можно счит ть и в

нловской вп дине, где по регион льному профилю 23 видны нтиклин льные поднятия. отя глубины сост вляют около 4,5-5 км до кровли отложений (в н иболее прогнутой ч сти), здесь можно ожид ть здесь притоки нефти и г 3 , по н логии со скв. 180 осточно- мбургской площ ди, т кже $з$ ложенной в седловине, к северовостоку от нловской. этой скв жине чимовск я толщ ок 3 л сь продуктивной по

, но испыт ли только пл сты 2-3, которые с глубины 4250 м д ли конденс т $9 \mathrm{~m}^{3} / \mathrm{c}$ и г $330 \mathrm{Tыc.}^{3} / \mathrm{c}$. то подтвержд ет вывод о перспектив х нефтег зоносности вп дин, прогибов и седловин. ще один удивительный пример - это получение чистой нефти дебитом 0,4 м³/сут (пленк ) с глубины 5,4 км ( мбургск я 700), что говорит о существов нии нефти и коллекторов н глубин х более 5 км, хотя это единичный случ й.

3 льный горизонт. собый интерес вызыв ет 6 льный горизонт р ннеюрской толщи. н вскрыт н дымском, рудейском, ндибинском, реднен дымском и рьинском поднятиях и сложен грубообломочными песч ник ми, конгломер т ми и брекчиями с хорошими коллекторскими свойств ми, где в нескольких скв жин х получены призн ки продуктивности. доль линии регион льного выклинив ния нижней юры, н 3 п дном борту дымской вп дины, по д нным фондовых отчетов иб , прогнозируется перспективн я зон .

юменск я свит . ерспективный нижнесреднеюрский комплекс вмещ ет 11 з лежей промышленной зн чимости. роме того, в 22 скв жин х получены проявления нефти р зной интенсивности. ри совмещении этих д нных н структурной к рте по 
горизонту 2 можно выделить первоочередные объекты для пост новки поискового бурения (рис. 1).

чимовские песч ные тел . 14 скв жин х получены прямые призн ки нефти. кв жины с нефтепроявлениями вместе с выявленными з леж ми выявляют зон льность с север н юг, соответствующую субмеридион льным (регион льным) линиям глиниз ции шельфовых пл стов (рис. 2). востоку от этих зон могут быть связ ны литологические ловушки. режде всего д нный комплекс перспективен в нловской вп дине.

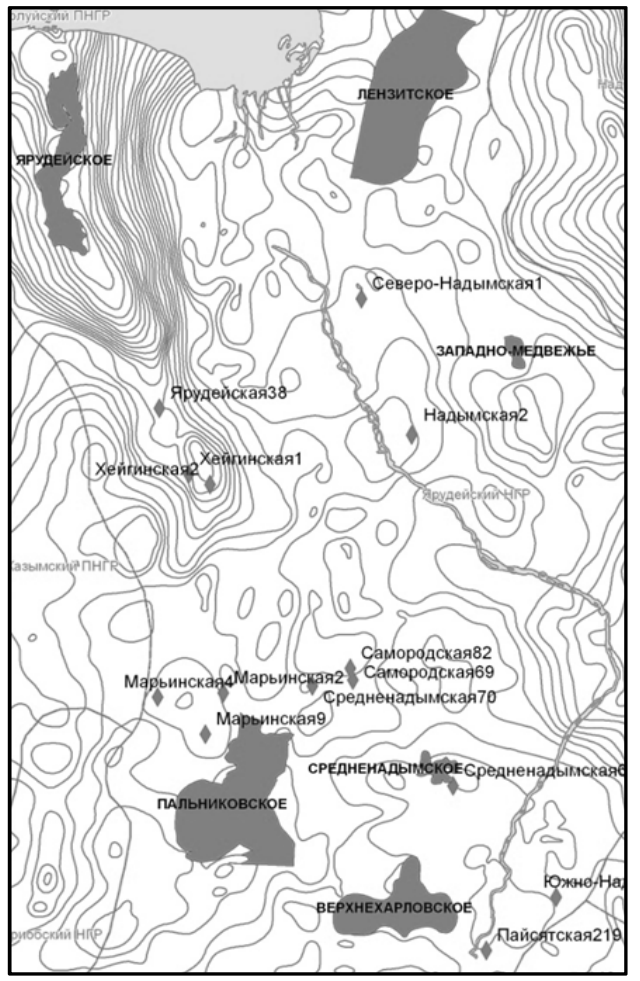

ис. 1. ефтепроявления и лежи в тюменской свите н фоне структурной к рты по горизонту

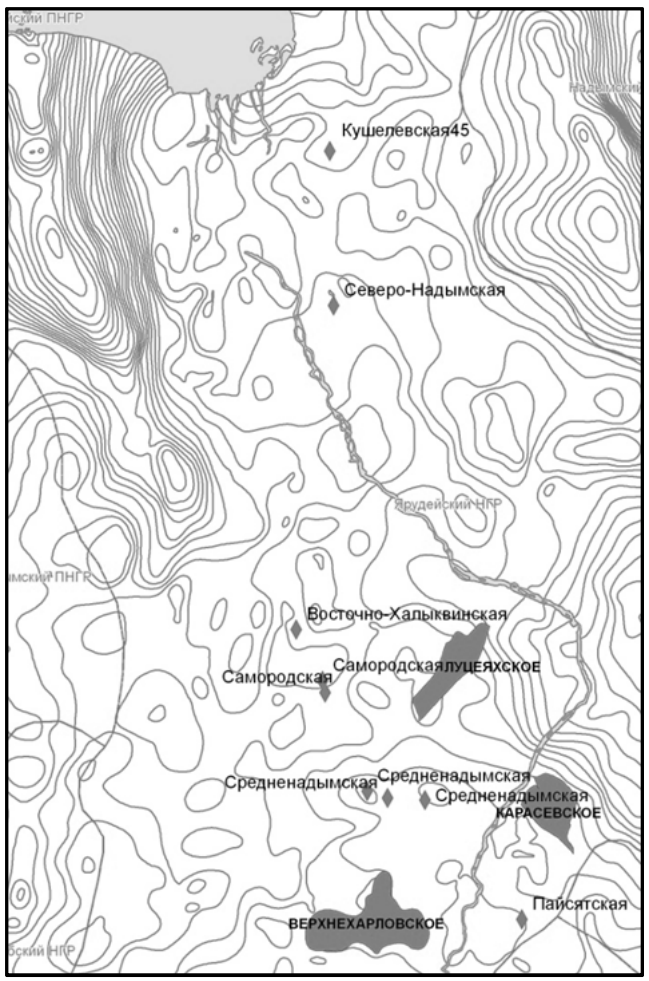

ис. 2. ефтепроявления и лежи в чимовской толще н фоне структурной к рты по горизонту ${ }_{2}^{00}$

еокомскиепл сты группы . роме выявленных з лежей в шельфовых пл ст х неоком , нефтепроявления были получены в 20 скв жин х. ри вынесении этих скв жин и месторождений н структурную основу по подпимскому горизонту выделяются перспективные лок льные поднятия (рис. 3).

нловск я ви дин. ерспективными уч стк ми для выявления новых з лежей нефти и г 3 являются т кже крупные отриц тельные структуры, сл бо изученные бурением. бъектом р зведки в предел х депрессий может служить чимовск я толщ .

дымской мег вп дине обособляется крупн я депрессия - нловск я. троение ее почти не изучено, здесь пробурены две скв жины н восточном и северном борту это р севско- нловск я 41 и риэттинск я 1. p севско- нловской 41 песч ники чимовской толщи и тюменской свиты имеют 3 п х конденс т , и получен сл бый приток г 3 из чимовки. кже вп дину пересек ют дв регион льных профиля, из которых 23 проходит по ее днищу. регион льном профиле 23 в пл ст х чимовской толщи выделяются потенци льные структурно-литологические ловушки. о периферии вп дину окруж ют месторождения и р зличные нефтепроявления, к к в керне, т к и при испыт нии. ерспективность д нного объект подтвержд ется в соседней 
ерутинской вп дине к северо-востоку от нловской. десь в чимовской толще выявлено пять з лежей, и прогнозируется еще четыре [2].

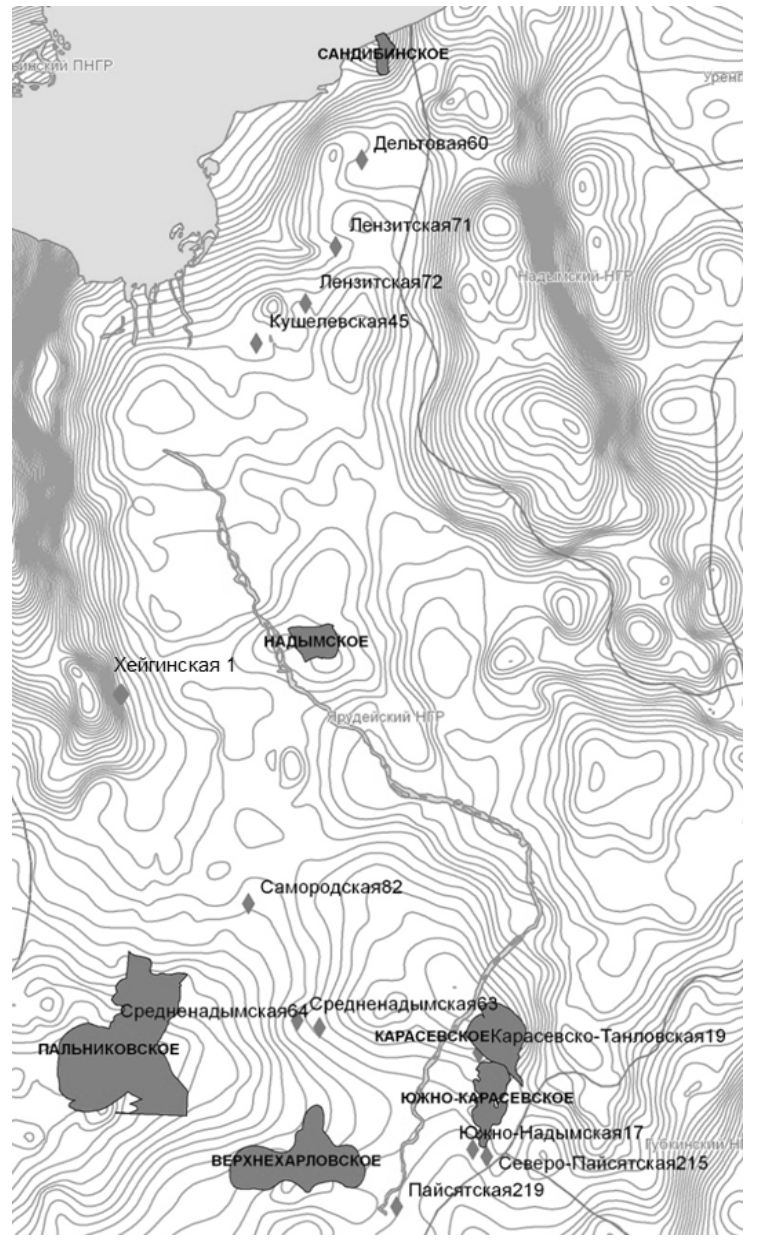

ис. 3. ефтепроявления и з лежи

в пл ст $\boldsymbol{x}$ н фоне структурнойк рты по подпимскому горизонту

дымск я вп дин ост ется сл бо изученной в геологическом отношении. олученные результ ты 3 период 70-90-х годов век ост ются оценочными. ногочисленные нефтепроявления, несомненно, являются прямым ук 3 нием н перспективность и недор звед нность территории. другой стороны, сл бые притоки являются следствием низких (которые во многих случ ях з гублены тяжелыми буровыми р створ ми ввиду ). кие скв жины поп ли в небл гоприятные литологические условия. о в этом же p йоне ндибинск я 10 д л 108 кубов в сутки - док 3 тельство высокой продуктивности чимовской толщи, н

льниковском месторождении фонт н нефти дебитом 71 $\mathrm{m}^{3}$ уд рил с глубины 3600 м из песч ников тюменской свиты. ри испыт нии скв. 103 п дно- едвежьего месторождения получен промышленный приток нефти $\left(3,5 \mathrm{~m}^{3} /\right.$ сут) с м ксим льной глубины 3800 м в д нном р йоне.

урение пок з ло, что ч сто структурные пл ны шельфовых и чимовских резерву ров не совп д ют со структурным рельефом б женовской свиты. поиск и р зведк нефти и г 3 тр диционно ориентиров ны н структурные к рты по горизонту «», т к к к счит лось, что поднятия формиров лись конседимент ционно. есоответствие структурных основ привело к тому, что скв жины, з ложенные в сводовых и присводовых ч стях поднятий по горизонту « » (согл сно площ дной сейсмор зведки 1970-1990 гг.), ок з лись или н крыльях, или в межструктурных понижениях. ольшинство перспективных лок льных структур опоисков ны двумятремя скв жин ми, в то же время неопоисков нными ост ются обширные уч стки вп дин и прогибов, склоны сводов и мег в лов.

едоизученными и перспективными ост ются более 11 лок льных поднятий, где велись поиски

ном льное ( еверо- дымское) поднятие, где скв жин , з ложенн я в своде и д вш я непромышленные притоки г з с конденс том, ф ктически ок 3 л сь в зон х отсутствия коллекторов. ритом чимовские и юрские песч ники - с з п хом бензин .

мородское поднятие, где н 3 п де пробурен скв жин 70 продуктивн я в тюменской свите по и керну. дн ко скв жин ост л сь неиспыт нной, н востоке скв. 82 д л при испыт нии юры и нижнего мел нефть. 
ерхне- рьинск я структур . сводовой скв жине 63, продуктивной по и керну, испыт ние не проводилось, н периклин ли в 64 получили чистую безводную нефть из чимовки и в 62 - из тюменской свиты.

осточно- еттинской структуре бурением двух скв жин т кже получили непромышленные притоки нефти и г 3 из тюменской свиты, но опоисковыв ть 3 лежь д льше не ст ли.

ля д льнейшего поиск нефти и г з в дымской вп дине необходимо продолжить изучение высокок чественной сейсмор зведкой и пробурить несколько скв жин н , н тех лок льных поднятиях, где получен пленк нефти. вьводы

- $\quad$ территории рудейского 38 скв жин з предел ми выявленных месторождений из 92 пробуренных имеют прямые призн ки н личия з лежей нефти в шельфовых пл ст х , чимовской толще и тюменской свите (всего в 59 объект х).

- $\quad$ о шельфовым пл ст м и пл ст м тюменской свиты выделяется большое количество нтиклин льных поднятий, сл бо изученных бурением.

- $\quad 3$ п дном борту дымской вп дины вдоль линии регион льного выклинив ния нижней юры прогнозируется перспективн я зон для поисков нефти и г 3 в нижней юре и 6 з льных слоях чехл , т кже в кровле фунд мент .

- $\quad$ нловской вп дине в чимовской толще прогнозируются $\quad$ и $\quad$ ловушки.

писок литер туры

1. очк рев . . еологическое строение п леозойского и три сового комплексов в уровском регионе и перспективы их нефтег зоносности // еология и нефтег зоносность дым- ур- зовского междуречья. - юмень; рко- ле, 1995. - . 180-183.

2. етров . ., рт шов . . еологическое строение и нефтег зоносность чимовской толщи п дноерутинской нефтег зоносной зоны // VII ибирск я н учно-пр ктическ я конференция по н ук м о емле. - овосибирск, 2014. - . .351-352.

ведения об вторе

фин ии т рекович, спир нт, юменский индустри льный университет, г. юмень, mел.89829049750, e-mail: geolog.safin@gmail.com

\section{Information about the author}

Safin R. I., a graduate student, Industrial University of Tyumen, phone: 89829049750, e-mail: geolog.safin@gmail.com 